\title{
A socio-psychological modal choice approach to modelling mobility and energy demand for electric vehicles
}

\author{
Khoa Nguyen ${ }^{*}$ and René Schumann \\ From The 9th DACH+ Conference on Energy Informatics \\ Sierre, Switzerland. 29-30 October 2020
}

\section{*Correspondence:}

khoa.nguyen@hevs.ch

HES-SO Valais Wallis, SiLab, Rue de

Technpole 3, 3960 Sierre,

Switzerland

\begin{abstract}
The development of efficient electric vehicle (EV) charging infrastructure requires modelling of consumer demand at an appropriate level of detail. Since only limited information about real customers is available, most simulations employ a stochastic approach by combining known or estimated business features (e.g. arrival and departure time, requested amount of energy) with random variations. However, these models in many cases do not include factors that deal with the social characteristics of EV users, while others do not emphasise on the economic elements. In this work, we introduced a more detailed demand model employing a modal choice simulation framework based on Triandis' Theory of Interpersonal Behaviour, which can be calibrated by empirical data and is capable of combining a diverse number of determinants in human decision-making. By applying this model on Switzerland mobility domain, an analysis on three of the most popular EV incentives from both supply and demand sides is provided, which aims for a better understanding of electro-mobility systems by relating its causes and effects.
\end{abstract}

Keywords: Agent-based modelling, Modal choice simulation, Electric vehicle, Behavioural theory

\section{Introduction}

The resurgence of electric vehicle (EV) provides an opportunity to address environmental concerns such as scarcity of energy resources, air pollution and global warming as they are known to be more energy efficient when compared with transitional means of transportations (Richardson 2013). On the other hand, this also poses challenges to the energy sector due to the significant increase in the overall electrical load demand in power distribution networks. Improved charging infrastructure is required to deliver the necessary energy for mobility while at the same time reducing the costs of operating (Ensslen et al. 2018). A large number of studies have planned to address the matter of predicting the realistic charging demand by modelling the EVs interaction with a smart grid, such as those

(C) The Author(s). 2020 Open Access This article is licensed under a Creative Commons Attribution 4.0 International License which permits use, sharing, adaptation, distribution and reproduction in any medium or format, as long as you give appropriate credit to the original author(s) and the source, provide a link to the Creative Commons licence, and indicate if changes were made. The images or other third party material in this article are included in the article's Creative Commons licence, unless indicated otherwise in a credit line to the material. If material is not included in the article's Creative Commons licence and your intended use is not permitted by statutory regulation or exceeds the permitted use, you will need to obtain permission directly from the copyright holder. To view a copy of this licence, visit http://creativecommons.org/licenses/by/4.0/. 
listed in Mwasilu et al. (2014); Daina et al. (2017). The main criticism of them is lack of realism because they rely too much on cost-benefit assumptions whilst ignore important psychological drivers of behaviour changes (Sovacool et al. 2015).

As an alternative approach, we have been developing an agent architecture that utilises the Triandis' Theory of Interpersonal Behaviour (TIB) (Triandis 1977) to provide a meaningful set of determinants that contribute to decision-making in socio-psychological research. TIB is a tri-level model that allows users to have the possibility of separating and highlighting the impacts of different psychological concepts to individuals and their networks. Our implementation platform - Behaviour-driven Demand Model (BedDeM) - aims to simulate short-term transportation modal choices (i.e. car, bus, tram, trains, walking, biking) of individual household in Switzerland in a variety of future scenarios. The current agent population contains a mapping of qualitative data in Swiss Household Energy Demand Survey (SHEDS) to all TIB's determinants, which is designed to reproduce the travelling patterns in Mobility and Transport Micro-census (MTMC) (Nguyen and Schumann 2019). In this paper, we combine the modal choice process with a predetermined charging behaviour to offer a practical insight into the correlation between EV mobility and charging demand in different policy settings, including: (1) increasing charging rate, (2) decreasing electric price, and (3) promoting the importance of using non-fossil vehicles (e.g. climate change campaign, reducing carbon footprint commitment). These policies target at either supply or demand side which allows us to observe the interchange effects between them in the model.

The structure of this paper is as followed: We first consider different methodologies that seek to model EV mobility and charging demand in "Related works" section. It is followed by a specification of our agent's decision-making architecture and implementation platform - BedDeM. The next "Experimental procedure" section describes an experiment in the context of mobility domain in Switzerland, whose main purpose is to show the response of EV demand to different price and non-price initiatives. We then summarise our work and suggest further researching directions in "Conclusion" section.

\section{Related works}

Across the transport, energy and power sector, modelling approaches are widely diverse and their focus is often not demanded itself, but the impacts of EV deployment (see the surveys in Daina et al. (2017); Xiang et al. (2019)). They have been developed and improved by transport demand researchers for many different purposes, such as forecasting EV ownership, testing effectiveness of government incentive, market potential etc. While the traditional approach focus on smart grid networks and demand response programs (Deng et al. 2015), transport modellers have now included travelling pattern and charging behaviour analysis in their system. In this section, we classify these agent-based models into two broad categories: (1) long-term, system-scale planning models and (2) short-period models.

\section{Long-term planning models}

They are run on a regional or national scale over the course of many years/decades and generally optimize the mix of electric generating units in a system given a set of boundary conditions, which can include the integration of EVs. Agent-based models in this category are mainly built upon the theoretical formulation of consumers behaviour or when their 
parameters can be estimated empirically, discrete choice models. Individual or household chooses between a complete set of exclusive alternatives (e.g. which vehicle to use or which service). Each of which has some utility derived based on its characteristics and the values that each places on these characteristics. According to the classical microeconomic theory, the individual will choose the alternative that maximises his/her utility (Rosenfeld and Kraus 2018). The concept of Random Utility is used to ensure the analyst can only identify the choice probability for each alternative, but not the choice outcome (Ben-Akiva et al. 1985).

Most of the discrete choice models utilising stated choice experiment data have identified several attributes affecting consumer decision when electric vehicles are amongst the alternatives in their choice sets, including price, recharging times/network density, power and emissions (Daziano and Chiew 2012). A popular approach in choice modelling is the Multinomial logit model, which has been widely used in vehicle adoption studies such as (Brownstone et al. 2000; Ewing and Sarigöllü 1998; Daziano 2013). In addition, the Hybrid choice modelling framework extends random utility to take into account latent (unobserved) quantities (e.g. social status concerns, environmental attitudes, safety and comfort) at the cost of increased data requirement (Ben-Akiva et al. 2002; Walker and Ben-Akiva 2002; Ben-Akiva et al. 2002).

The use of long-term planning methodology in electric mobility should be mainly focused on forecasting the EV stock on the road and their spatial distribution. This could be beneficial for the type of analysis when yearly time scales are of interest, e.g. annual energy consumption, or yearly air quality impact of vehicle deployment. On the contrary, it is not suited for the direct study of charging patterns in time and space and the impact of charging demand peaks on power grids or accurately estimate the emission associated with EV charging, given the dynamic of electricity generation of grid systems.

\section{Short-period models}

These models take hourly historical data as well as driving patterns to assess the ability of the system to match supply and demand over the short and medium-term. However, due to the lack of data and privacy concerns, charging behaviours or strategies are often not explicitly modelled, but predetermined by scenarios based on actual policy variables (e.g. tariff structures, infrastructure availability, characteristics of the facilities). Examples include uncontrolled (i.e. uncoordinated) charging, delayed (i.e. night) charging, and offpeak charging. Another approach involves implementing optimised strategies in an agentbased fashion assuming that EVs are agents, who choose the minimum-costing schedule that enable the execution of their journeys between charging opportunities. The models in this category can be further divided into three smaller classes based on their substantive methodological differences: (1) Summary travel statistics, (2) Markov chain theory and (3) Discrete choice models.

Summary travel statistics models: Summary statistics or empirical distributions are extracted from national, regional or metropolitan travel surveys to generate deterministic or stochastic vehicle use patterns. These are then combined with charging behaviour scenarios as mentioned above to generate mobility profiles. For example, Zakariazadeh et al. generate seven archetypal driving patterns based on statistics from a survey in a real town, each of which has trip durations and specific times during which EV has parked at 
home and work (Zakariazadeh et al. 2014; 2015). The model of Mullan et al. use the average vehicle distance travelled in Western Australia (40 miles), and a charging time of $4 \mathrm{~h}$ at $1.5 \mathrm{~kW}$ to refill the battery for that distance. Besides, random delays in charging start times and predetermined charging period (e.g. 16:00-23:00 or 23:00-7:30) were utilised to simulate consumer behaviour (Mullan et al. 2011). Other similar applications of using empirical distributions to represent variability in vehicle mileage and charging times can be found in Dallinger et al. (2011); Dallinger and Wietschel (2012); Wang et al. (2011); Qian et al. (2010); Druitt and Früh (2012). As a trip based approach, these models lack a consistent travelling schedule and therefore, only suitable for studies that require less accuracy along the temporal and spatial dimensions (e.g. planning for future capacity). One other weakness is the effects on travel patterns of charging demand management is often neglected due to the exogenous vehicle usage patterns generation (Daina et al. 2017). In addition, the inherent load flexibility of aggregate demand could be lost if the travelling patterns variability is reduced by the use of summary statistics only.

Markov chain models: Soares et al. proposed an alternative approach to generating a consistent vehicle pattern by using a discrete-time state Markov Chain to define a vehicle state of EV agent in each 30-minute interval over one year (Moreira et al. 2011). These states include driving, parking in a residential, commercial or industrial area. Initial states and transition probabilities are obtained from statistical data regarding traffic patterns in the region of analysis (in this case the Porto area in Portugal). Further examples include (Shepero and Munkhammar 2018; Wang and Infield 2018). The disadvantage of these models is their lack of the theoretical link between activity participation and travelling demand. Hence, it appears more conceptually difficult to model the response of EV users to the variety of factors potentially indirectly affecting their charging patterns (e.g. temperature, weather) (Daina et al. 2017).

Activity-based models: Fundamentally, they are based on a perspective that human seeks to participate in activities travel behaviour represents just a facet of complex patterns of the behaviours that an analyst can observe. With a charging behaviour component integrated, these models allow the effect of charging demand management policies both on charging and travel patterns to be simulated without relying on predefined charging behaviour scenarios. One prominent example is the integration of an EV and power system simulation called PMPSS with MATSim, a tool for agent-based activity-based transport modelling (Waraich et al. 2013; Galus et al. 2012). In MATSim, a population of agents is generated from census data. Each of which is assigned a specific vehicle (battery EV, a plug-in hybrid EV or another type) and schedule of trips and activities. It uses utility maximisation and a co-evolutionary algorithm to optimise the planning of route, timing, mode and destination. PMPSS, which has its model of EV agents, provides feedback as electricity price signal containing network congestion information to the MATSim scheduler and determines if the load from charging infringes any physical conditions. In another study, Knapen et al. use the FEATHERS to generate activity-travel schedule instead of real diaries (Knapen et al. 2011). Similar works can be seen in Hodge et al. (2011); Nourinejad et al. $(2016$.

Within the framework, practitioners have introduced improvements mainly aimed to obtain more reasonable result at the aggregate level, rather than improve behavioural 
modelling at the individual level. The current representation of the utility attained by EV agent is theoretically appealing but lacks policy sensitivity when it comes to evaluating the potential effects of charging demand strategies on travel patterns. Hence, further research is needed on the design of price and non-price incentives for charging behaviour including but not limited to dynamic pricing, product bundling (e.g., vehicle and charging infrastructure access) and regulatory interventions (Daina et al. 2017). As an effort to find the solution, this paper describes an agent-based modal choice framework that has a variety of socio-psychological determinants and allows empirical data to be incorporated for a case study. Hence, it provides a flexible platform to test and understand the effects of different global policies and infrastructures on individuals' decision-making as well as their society.

\section{The behaviour-driven demand model (BedDeM)}

As an effort to produce a more comprehensive agent architecture that can utilise qualitative data to capture consumer behaviour, we decide to implement Triandis' Theory of Interpersonal Behaviour (TIB) (Triandis 1977) in our platform - Behaviour-driven Demand Model (BedDeM) - by using the Repast library (The Repast Suite) for agentbased modelling. TIB is chosen due to its expressibility as a theory for human behaviour and ability to calculate expected utility with its tri-level form (see Fig. 1). BedDeM's first application is in the domain of mobility, whose main purpose is to generate daily mobility demands at the individual household level based on their modal choices for daily trips. In this section, we first detail the decision-making mechanism, which implements the TIB to derive utility values for a set of alternatives options. It is then followed by an overview of our agent architecture framework and description for the mapping of empirical data in the context of mobility demand.

\section{Decision-making process}

To create a system that can mimic the function of human society, the first question to address is how to model individual behaviour. In psychology, different theories in the school of cognitive model describe this process, e.g. Ajzen and Fishbein's Theory of Reasoned Action (Fishbein et al. 1975) and Ajzen's (1991) Theory of Planned Behaviour

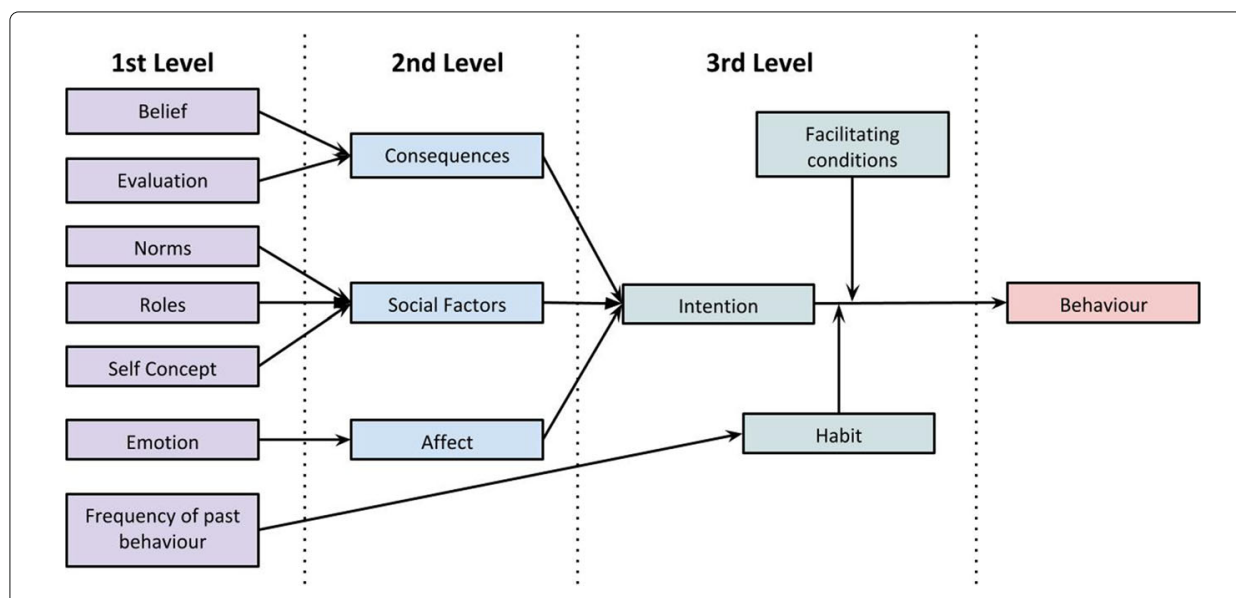

Fig. 1 Triandis' tri-level model following (Triandis 1977) 
(Ajzen 1991), etc. TIB (Triandis 1977) provides a more comprehensive set of determinants and the ability to combine these to form a complete picture of human decision-making. This set is also flexible enough to reflect other behaviour theories by exchanging the determinants and/or assigning weights to mark their contribution to the agent's reasoning process.

A full decision-making cycle with TIB Module is illustrated in Fig. 2. An agent is first given an isolated decision-making task from the list that is sequentially executed. Its internal state is then combined with means provided by the external environmental state to generate a set of possible propositions/options. As an example using our case study below, agents are given a set of accessible transportation (e.g. diesel car, train, bus, walking, etc.), which can be initialised in their capabilities in the knowledge/memory using data mapping from microcesus (see "Experimental procedure" section). These capabilities can be updated when observations are made from external environment (see "Agent architecture overview" section for more details). For all determinants $(d)$ in TIB, each option (opt) is then given a utility value which comes from comparing its properties with other's $\left(U_{d}(o p t)\right)$. In the first level, this value can be in the form of a real numerical system (for determinants such as price or time) or ranking function (for determinants such as emotion). Either of which can be calculated from empirical data (e.g. census, survey) or calibrated with expert's knowledge and stakeholders' assessment. The results for these determinants are then normalized and multiplied with an associated weight (called $w_{d}$ ); the sum of which becomes the referenced value for the option in the next level. This process is captured in the following equation:

$$
E U_{d}(\text { opt })=\sum_{a=1}^{A}\left(E U_{a}(\text { opt }) * w_{a} /\left(\sum_{o=1}^{O} E U_{a}(o)\right)\right)
$$

$E U_{d}(\mathrm{opt})$ is the utility value of an option (opt) at determinant $d . A$ is the set of all ancestors of $d$ (i.e. determinants connects with $d$ in the previous level). $O$ is the set of all available options. $w_{a}$ is the weight of ancestor $a$. In this case, the weight represents the importance of a decision-making determinant compare to others at the same level and emphasizes the heterogeneity of individuals. It also allows the modeller to express a certain theory by cutting determinants that are not relevant to a case study, i.e. setting their

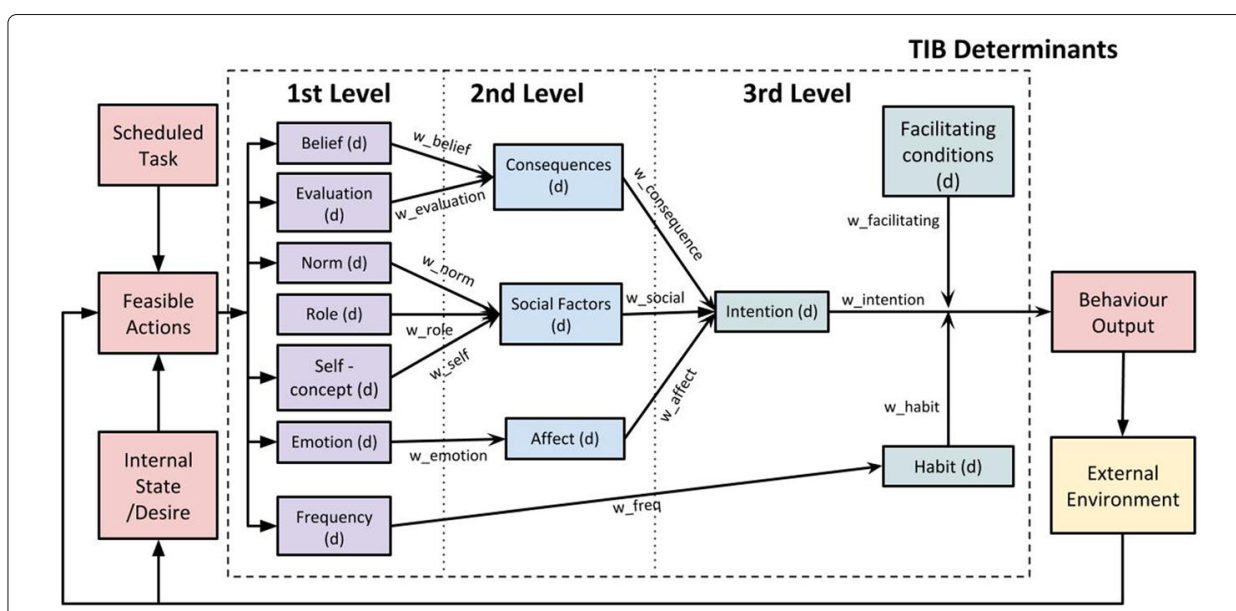

Fig. 2 Agent decision-making mechanism with TIB Module 
weights to 0 . The combination process then continues until it arrives at the behaviour output list, whose utility values can be translated to the probabilities that the agent will perform that option. If the agent is assumed to be deterministic, it picks the option that is correlated to the highest or lowest utility depending on modeller's assumptions.

To translate the determinant Belief and Evaluation (1st Level in Fig. 2) to a practical application, we use the concept of consequences, i.e. cost or result of an action. In Triandis (1977), Triandis defines Belief as the chance (or percentage) that a consequence will happen. The Evaluation gives the expected value to that consequence. The running example below and "Experimental procedure" section focus on mobility and use utility values as a cost function, i.e. agents prefer the lower utility option. Hence, we interpret determinant Evaluation as cost of choosing a mode of transportation in term of price and duration. In addition, for this stage of BedDeM, an agent is assumed to belief completely in its evaluation (Belief $=100 \%$ ), i.e. there is no extra price or delay in time. Further development can allow these beliefs to be updated with the feedback from external environment, such as the agent was late on previous trip.

\section{Running example}

Table 1 shows a running example in mobility domain which follows the TIB determinants mapping in Fig. 2. An agent needs to make a working trip from Sion to Sierre/Siders and has access to 3 options: using car, taking train or bike, which is assigned from data collected from (Mobility and Transport Microcensus 2017) (more details can be seen in "The mobility simulation" section). In addition, $E U$ is a cost function, i.e. option that has smaller value is preferred. As explained above, the agent beliefs and evaluates the consequence/cost for this journey based on two criteria, namely Price and Duration. It expects the car option would have the price around 4 Swiss Franc, and so $E U_{\text {Price }}(\mathrm{car})=$ 4. Correspondingly, $E U_{\text {Price }}($ train $)=3$ and $E U_{\text {Price }}($ bike $)=0$. Their total value, $\sum E U_{\text {Price }}$, is 7 . The estimations for duration are $E U_{\text {Duration }}($ car $) \approx 0.3, E U_{\text {Duration }}($ train $) \approx 0.2$ and $E U_{\text {Price }}($ bike) $\approx 1$; the sum of which is 1.5 . According to (Swiss Household Energy Demand Survey (SHEDS) 2017), the agent has $w_{\text {Price }}$ and $w_{\text {Duration }}$ are 2 and 4 respectively. By applying Eq. 1, the new expected value in next level $\left(E U_{\text {Consequences }}\right)$ of car would be $=$ $4 / 7^{*} 2+0.3 / 1.5^{*} 4 \approx 1.94$, train would be $3 / 7^{*} 2+0.2 / 1.5^{*} 4 \approx 1.39$, and bike would be $0 / 7^{*} 2$ $+1 / 1.5^{*} 4 \approx 2.67$. Hence, according to determinant Consequence, train would have the highest chance to be picked, followed by car and bike.

For non-measurable value such as Norm, the agent uses the concept of reputation (popularity) to rank the options: $E U_{N o r m}(\operatorname{train})=1, E U_{N o r m}(\mathrm{car})=2, E U_{N o r m}$ (biking) $=3$ (best to worst); the sum of which is 6 . The same values are applied for determinant Self-concept, which is based on the clustering process described in "The mobility simulation" section. On the other hand, the agent might have an environmental consciousness and rank these mode in the opposite order, e.g. $E U_{\text {Role }}($ bike $)=1, E U_{\text {Role }}($ train $)=2$ and $E U_{\text {Role }}($ car $)=3$. According to the data in (Swiss Household Energy Demand Survey (SHEDS) 2017), $w_{\text {Norm }}$ $=3, w_{\text {Role }}=2$ and $w_{\text {Role }}=3$. By combining these social factors using Eq. 1, we then have $E U_{\text {Social }}($ car $)=2, E U_{\text {Social }}($ train $) \approx 2.67$ and $E U_{\text {Social }}($ bike $) \approx 3.33$. Because expected utility is a cost function, i.e. agent prefer lower value, inverse values of determinant Frequency and Facilitating Conditions are used in Table 1.

The process continues with other determinants on different levels (see Table 1 and Fig. 2) until the agent reaches its behaviour output, where expected values are $E U(c a r)$ 
Table 1 Running example of an agent's decision-making for a $18 \mathrm{~km}$-journey from Sion to Sierre/Siders. Note that the expected utility is a cost function, i.e. agent prefer lower value ${ }^{1}$

\begin{tabular}{|c|c|c|c|}
\hline Level & Determinant & w & EU \\
\hline \multirow[t]{7}{*}{1 st } & $\begin{array}{l}\text { Evaluation (Price - Swiss franc), } \\
\text { Belief }=100 \%\end{array}$ & 2 & $E U($ car $)=4 E U($ train $)=3 E U($ bike $)=0$ \\
\hline & $\begin{array}{l}\text { Evaluation (Duration - hours), Belief } \\
=100 \%\end{array}$ & 4 & $E U($ car $) \approx 0.3 E U($ train $) \approx 0.2 E U($ bike $) \approx 1$ \\
\hline & Norm (similarity with others) & 3 & $E U($ train $)=1 E U($ car $)=2 E U($ bike $)=3$ \\
\hline & Role (environmental friendliness) & 2 & $E U(c a r)=3 E U($ train $)=2 E U($ bike $)=1$ \\
\hline & Self-concept (personal preference) & 3 & $E U(c a r)=1 E U($ train $)=2 E U($ bike $)=3$ \\
\hline & Emotion (enjoyment) & 1 & $E U($ car $)=1 E U($ train $)=2 E U($ bike $)=3$ \\
\hline & $\begin{array}{l}\text { Frequency (past similar trips - note } \\
\text { that lower value means more } \\
\text { usage) }\end{array}$ & 3 & $E U($ car $)=0 E U($ train $)=0 E U($ bike $)=1$ \\
\hline \multirow[t]{3}{*}{$2 s t$} & Consequence (Evaluation + Belief) & 4 & $\begin{array}{l}\text { EU(car) }=4 / 7^{*} 2+0.3 / 1.5^{*} 4 \approx 1.94 E U(\text { train }) \\
=3 / 7^{*} 2+0.2 / 1.5^{*} 4 \approx 1.39 E U(\text { bike })=0 / 7^{*} 2+ \\
1 / 1.5^{*} 4 \approx 2.67\end{array}$ \\
\hline & $\begin{array}{l}\text { Social factors (Norm + Role + } \\
\text { Self-concept) }\end{array}$ & 2 & $\begin{array}{l}\text { EU }(\text { car })=1 / 6^{*} 3+3 / 6^{*} 2+1 / 6^{*} 3=2 \text { EU }(\text { train }) \\
\left.=2 / 6^{*} 3+2 / 6^{*} 2+2 / 6^{*} 3 \approx 2.67 \text { EU (bike }\right)= \\
3 / 6^{*} 3+1 / 6^{*} 2+3 / 6^{*} 3=\approx 3.33\end{array}$ \\
\hline & Affects (Emotion) & 2 & $\begin{array}{l}\left.E U(\text { car })=1 / 6^{*} 1 \approx 0.17 \text { EU(train }\right)=2 / 6^{* 1} 1 \approx \\
0.33 E U(\text { bike })=3 / 6^{*} 1=0.5\end{array}$ \\
\hline \multirow[t]{4}{*}{$3 \mathrm{rd}$} & $\begin{array}{l}\text { Intention (Consequence + Social } \\
\text { factors }+ \text { Affect) }\end{array}$ & 4 & $\begin{array}{l}E U(\text { car })=1.94 / 6^{*} 4+2 / 8^{*} 2+0.17 / 1^{*} 2 \\
\approx 2.13 E U(\text { train })=1.39 / 6^{*} 4+2.67 / 8^{*} 2 \\
+0.33 / 1^{*} 2 \approx 2.26 E U(\text { bike })=2.67 / 6^{*} 4+ \\
3.33 / 8^{*} 2+3 / 1^{*} 2 \approx 3.28\end{array}$ \\
\hline & Habit (Frequency) & 3 & $\begin{array}{l}E U(\text { car })=0 / 1 * 3=0 \text { EU(train })=0 / 1 * 3=0 \\
E U(\text { bike })=1 / 1 * 3=3\end{array}$ \\
\hline & $\begin{array}{l}\text { Facilitating conditions (lower mean } \\
\text { easier to access) }\end{array}$ & 2 & $\begin{array}{l}E U(\text { car })=0 E U(\text { train })=1 \text { (agent is far from } \\
\text { train station) } E U(\text { bike })=0\end{array}$ \\
\hline & Behaviour output & & $\begin{array}{l}E U(\text { car })=2.13 / 7.67^{*} 4+0 / 2^{*} 3+0 / 2^{*} 2 \approx \\
1.11 E U(\text { train })=2.26 / 7.67^{*} 4+0 / 2^{*} 3+1 / 2^{*} 2 \\
\approx 2.18 E U(\text { bike })=3.28 / 7.67^{*} 4+1.5 / 2^{*} 3+ \\
3 / 2^{*} 2 \approx 6.96\end{array}$ \\
\hline
\end{tabular}

$\approx 1.11, E U($ train $) \approx 2.18$ and $E U($ bike $) \approx 6.96$. This indicates that car would be the best option for this agent. We choose this example to highlight the importance of social factors in decision-making because the best choice would have been using the train if the agent only makes evaluation based on Price and Duration (see 2nd Level in Table 1).

\section{Agent architecture overview}

An agent's main components and their functions are illustrated in Fig. 3. When a task is assigned, the Perception observes the current state of the environment, other agent preferences and combines them with the agent's internal state to produce a list of available options. They are given to the Decision-making unit to be evaluated using the functions (or preferences) from the Memory. Details of this process have been described in previous "Decision-making process" section. The Communication component then utilises this result to create a behaviour output and communicate this to the environment and others. The environment can then provide feedback(s) based on the numbers of demands and nature of the system associated with the action. For example, a charging station that already has the number of demands over a threshold will decline the next request and causes dissatisfaction among customers. Agent remembers these action results and

\footnotetext{
${ }^{1}$ Data collected from (Google Map; Rome2rio website; Mobility and Transport Microcensus 2017; Swiss Household Energy Demand Survey (SHEDS) 2017)
} 


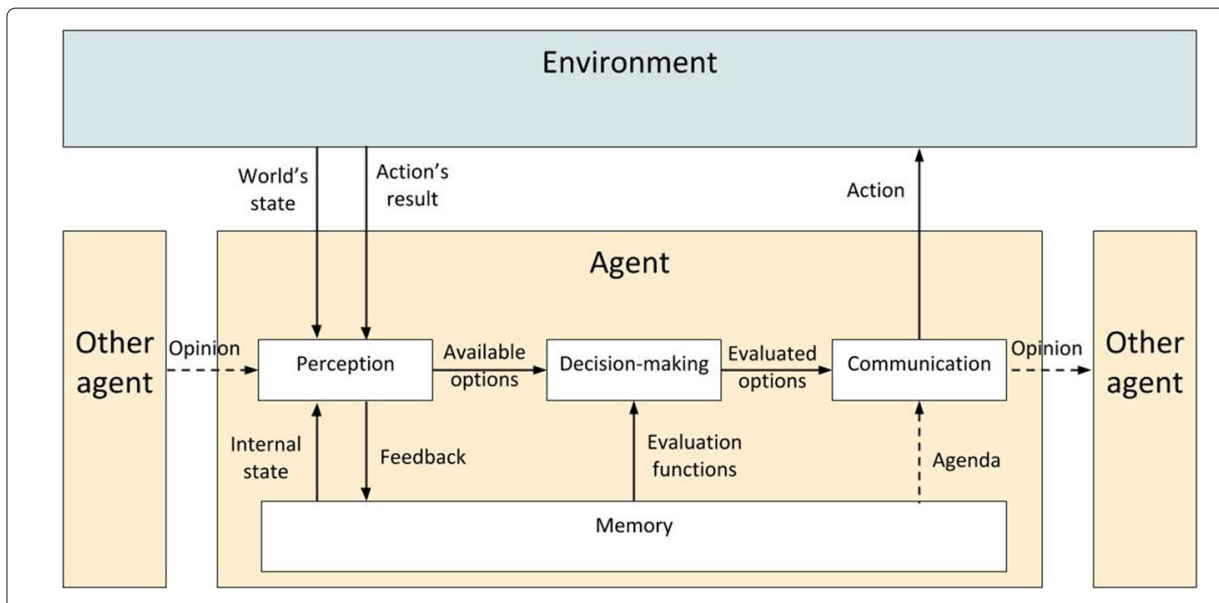

Fig. 3 Overview of agent's architecture

feedbacks in the Memory, which can then be used to modify the probability of expected values in future decision-making. In the case study in "Experimental procedure" section, we consider the effect of feedback to determinants Emotion (i.e. satisfactory or enjoyment when using the mode of transport) and Frequency (i.e. number of past trips).

\section{The mobility simulation}

As shown in Fig. 4, BedDeM consists of two processes. In the configuration phase, we applied cluster analysis on the Swiss Household Energy Demand Survey (SHEDS) (Weber et al. 2017) and the Mobility and Transport Micro-census (MTMC) (ARE/BfS 2017) to generate the mobility profiles, which are configuration vectors for agents in the simulation. There is a total of 3,080 agents, which are representatives for different geographical regions in Switzerland. Each associate with a weight-to-universe number that can be used to scale up the final results to the national level. More details can be seen in (Bektas and Schumann 2019).

This data is then passed to a controller in the simulation stage. From Eq. 1, there are two elements that are required from this data: (1) Expected utility of a determinant $(E U)$ is extracted from MTMC and, (2) the determinant weight $(w)$ is based the answers given in SHEDS. A sample of this process for the first level determinants is included in Fig. 4. More

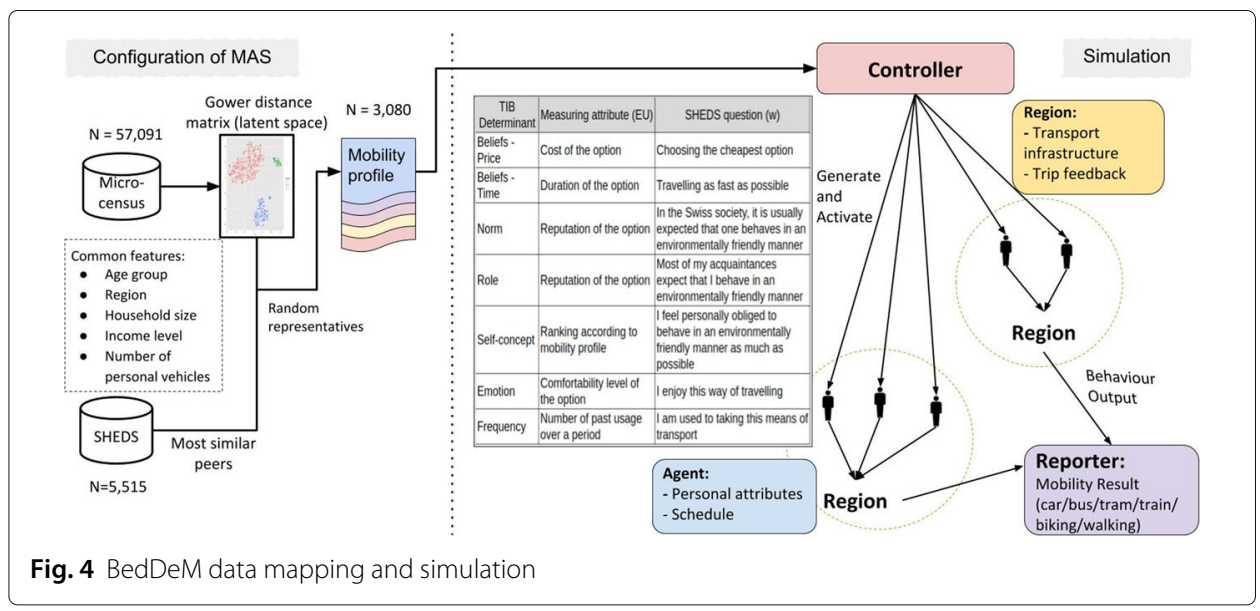


details of the data mapping and agent's parameters calibration can be found in (Nguyen and Schumann 2019).

The agents are then assigned to their respective regions, which contain information about the available public transportation and can be used to reflect the dynamic change in mobility infrastructure (e.g. charging rate, location of stations) with regard to the simulating time. A weekly schedule is also derived for each agent from the MTMC to provide a way to calculate all relative attributes for a trip (including purpose, distance, execution time). Depend on the availability of transportation systems, the set of options in decision-making often consists of rail, bus, tram, car, walking, biking. The agent's main purpose is to select a mode of transportation to perform a task on its schedule. There is also an option of not performing the scheduled activity due to the constraints from the agent's states or environment (e.g. exhaustion of budget or exceeded travelling time on all available modes).

\section{Experimental procedure}

This section focus on the usage of BedDeM to perform experimentation regarding the effects of policy on daily mobility and charging demand, which is measure in a daily average of the total kilometres travelled and kilowatt-hour ( $\mathrm{kWh}$ ) consumed. In the next subsection, we describe a base case with agents following the decision-making architecture in "Decision-making process" section and predetermined charging behaviour. It is followed by a description of three hypothetical scenarios. We then analyse the results and provide some discussion on the competency of BedDeM as an EVs modelling tool and suggests some extensions for future development.

\section{Setup}

For the purpose of modelling electric demand generated from travelling, we include a predetermined charging mechanism: When an agent reports an activity with personal EV, an electric consumption counter is increased to keep track of the daily required amount. If it is the last activity of the day, the agent will start charging at the following hour, i.e. a type of uncoordinated charging, and continues until its demand is met or the next trip requires the vehicle. If the demand is met, the expected value of Emotion determinant increases as an effect of feedback from the environment (see Fig. 3). Each agent has a schedule of a typical week and their parameters are calibrated to the data in MTMC (see "The mobility simulation" section). Since BedDeM is not a routing model, we do not consider the case in which agents can charge between trips; though it could be added to the decision-making process in future development. In addition, as agents are assigned with their own list corresponding/accessible modes of transportation for the simulated week by using data from MTMC, they do not perform long-term decision-making, such as buying new type of private car (i.e. switching Diesel to EV). Because agents represent households, there are some cases that they have access to both EV and non-EV vehicle. In this study, we focus on examine effects of different policies on agent's decision between different modes of transportation (i.e. car, tram/train, bus, biking, walking and others) which can subsequently, change the demand of usage for EV vehicles.

For the base case, a charging capacity - $E_{\text {charge }}$ - is preset at $3.7 \mathrm{kWh}$ for all stations, whose locations are captured from the PlugShare Online Platform (see Fig. 5). This $E_{\text {charge }}$ is the standard low bound offered to a customer by a station in Switzerland (Brenna 


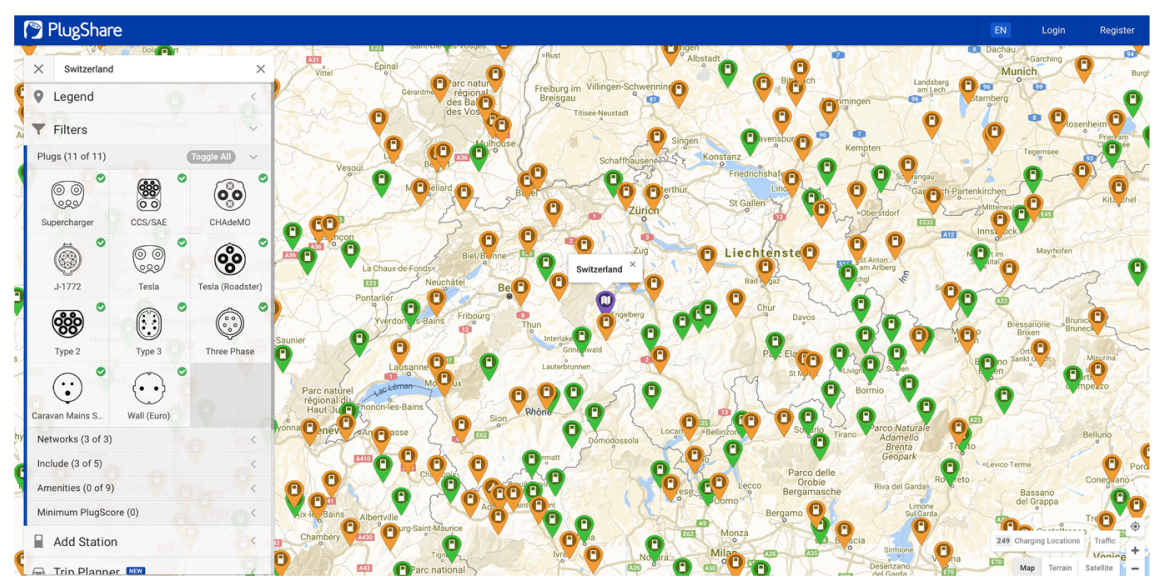

Fig. 5 A map of charging station in Switzerland from the PlugShare Online Platform (Plugshare 2020)

et al. 2014). Therefore, it can be assumed that overloading scenarios are improbable in the experiment results. As a possible future extension, we could assign a specific charging rate by the hour of the day for each station to observe the difference in territorial demand.

As suggested by Sierzchula et al. (2014), we select three incentives that are widely utilised in many countries and can take advantage of different elements in our model from both supply and demand sides. Their application to BedDeM are summarised in Table 2 . The first policy is to increase the $E_{\text {Charge }}$ to 7,11 and $22 \mathrm{kWh}$ at the station in the region that has most demand according to the base case. This is the next step up from the preset value $(3.7 \mathrm{kWh})$ in the study of (Brenna et al. 2014). Its main purpose is to boost the efficiency of infrastructure, reduce charging time and improve customer's satisfaction. Following (Swissgrid 2020), the next policy is decreasing the charging price, which is only applicable to private vehicles. In this case, the expected utility of the Price determinant - $E U_{\text {Price }}(E V s)$ - is decreased by quarterly percentages. Finally, we consider a scenario in

Table 2 Scenarios and their modified variables

\begin{tabular}{|c|c|c|c|c|}
\hline Scenario & Target & Variable & Value & Case number \\
\hline \multicolumn{4}{|l|}{ Base case } & 0 \\
\hline \multirow[t]{3}{*}{ Charging rate increased } & $\begin{array}{l}\text { Stations of the } \\
\text { region has most } \\
\text { demand }\end{array}$ & ECharge & $7 \mathrm{kWh}$ & 1.1 \\
\hline & & & $11 \mathrm{kWh}$ & 1.2 \\
\hline & & & $22 \mathrm{kWh}$ & 1.3 \\
\hline \multirow[t]{4}{*}{$\begin{array}{l}\text { Electric charging price } \\
\text { decreased }\end{array}$} & Global & $E U_{\text {Price }}(E V S)$ & $-25 \%$ & 2.1 \\
\hline & & & $-50 \%$ & 2.2 \\
\hline & & & $-75 \%$ & 2.3 \\
\hline & & & $-100 \%$ & 2.4 \\
\hline \multirow[t]{4}{*}{ Climate awareness improved } & $\%$ of population & $\begin{array}{l}\text { Wrole }=5 \\
\text { (maximum) for } \% \\
\text { of population }\end{array}$ & $25 \%$ & 3.1 \\
\hline & & & $50 \%$ & 3.2 \\
\hline & & & $75 \%$ & 3.3 \\
\hline & & & $100 \%$ & 3.4 \\
\hline
\end{tabular}


Table 3 Result of daily average mobility demand $\left(10^{6} \mathrm{~km}\right)$ by engine type in scenarios of charging rate increased

\begin{tabular}{lllll}
\hline Case number & \multicolumn{4}{l}{ Average daily mobility demand $\left(\mathbf{1 0 ^ { 6 }} \mathbf{k m}\right)$ by engine type } \\
\cline { 2 - 5 } & Electric/Hybrid & Diesel/Gasoline & Walk/Bike & Train/Tram \\
\hline 0 & 56.511 & $3^{\prime} 016.546$ & 172.374 & 576.450 \\
\hline
\end{tabular}

which agents have their environmental awareness improved (through climate policies and campaigns). It affects the weight of Role determinant $\left(w_{\text {Role }}\right)$ which indicates how important it is for an agent to be environmentally friendly. According to the study in UNIVOX (UNIVOX 2020), the value of $w_{\text {Role }}$ is set at maximum (in the scale of 1-5) for a quarterly percentage of the agent population (selected randomly). We theorise that these agents will tend to prefer using EVs or public transports rather than fossil-fuelled vehicles.

\section{Results}

We present the result of daily mobility demand for a typical working day of a week in Tables 4, 5, 6, and correspondingly, charging demand at different hours of the day in Figs. 7, 8 and 9. The case numbers are following the one in Table 2. As mentioned above, there are some agents representing households that have access to both EV and non-EV private vehicles. In which case, they can make a switch between these modes. However, most of the differences are due to interchange between the demand of different transportation types, i.e. private to public/walking or vice versa.

\section{Base case (see Table 3 and Fig. 6)}

As we capture data in 2015, the availability of EVs in Switzerland is relatively small compared to other means of transport. Their daily demand is roughly 57 million kilometres, which accounts for $15 \%$ of daily kilometres travelled by private vehicle owners. In term of charging demand, there are several peaks at the hour of 10, 13 and 18; which represent the time after travelling to work, lunch and when people finish a day of work. These peaks are roughly around 45-70 MWh and tend to go down after one to three hours. There is also a phenomenon of overnight charging from $6 \mathrm{pm}$ to midnight.

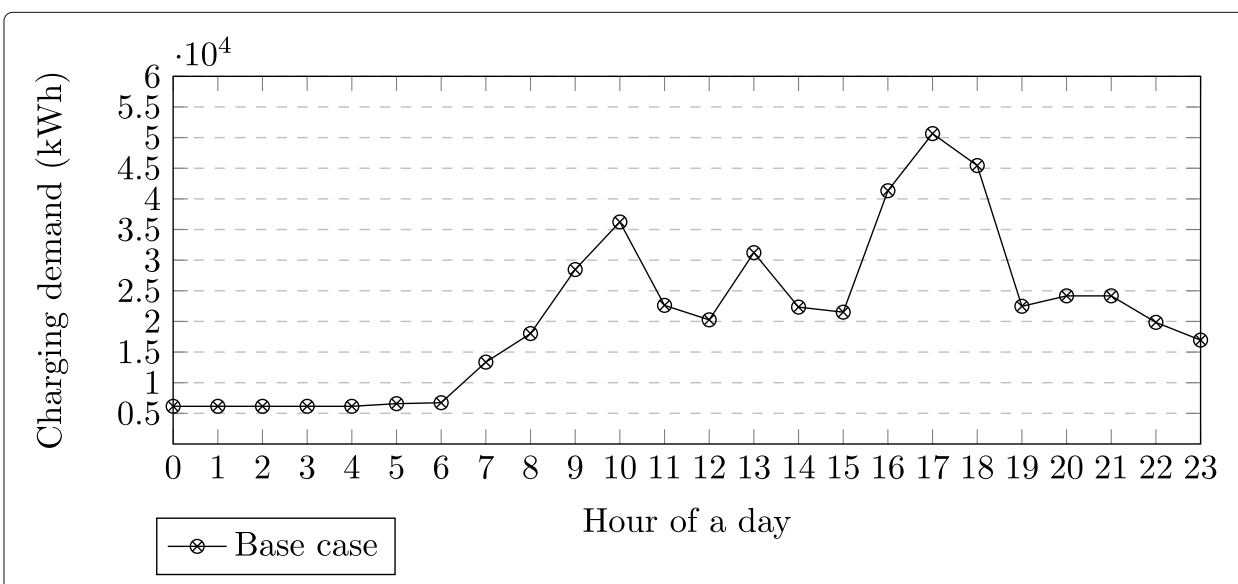

Fig. 6 Comparison of charging demand in the base case and in scenario that electric tariff is decreased 
Table 4 Result of daily average mobility demand $\left(10^{6} \mathrm{~km}\right)$ by engine type in scenarios of charging rate increased

\begin{tabular}{llllll}
\hline Case number & \multicolumn{4}{c}{ Value of $E_{\text {Charge }}(\mathbf{k W h})$} & \multicolumn{4}{c}{ Average daily mobility demand $(\mathbf{1 0} \mathbf{k} \mathbf{k m})$ by engine type } \\
\cline { 3 - 6 } & & Electric/Hybrid & Diesel/Gasoline & Walk/Bike & Train/Tram \\
\hline 0 & 3.7 & 56.511 & $3^{\prime} 016.546$ & 172.374 & 576.450 \\
1.1 & 7.0 & 56.850 & $3^{\prime} 015.918$ & 172.461 & 575.246 \\
1.2 & 11.0 & 56.860 & $3^{\prime} 015.774$ & 172.421 & 576.380 \\
1.3 & 22.0 & 57.187 & $3^{\prime} 015.085$ & 172.370 & 576.409 \\
\hline
\end{tabular}

\section{Charging rate increased (see Table 4 and Fig. 7)}

An increase in charging rate to $7 \mathrm{kWh}$ for stations of the region that has most charging demand drives the mobility of EV up by about 339 thousand kilometres. They are mainly shifted from the figures of Diesel usage and Train/Tram due to the increase in satisfaction and better service for EVs. In term of charging demand, an additional peak appears at $5 \mathrm{pm}$. Moreover, there are several increases in off-peak hours. The similar story applies to the second case with the charging rate reaches $11 \mathrm{kWh}$, though more throughput is required at charging station. In the final case with $E_{\text {Charge }}$ preset at $22 \mathrm{kWh}$, there is a small surge in mobility demand of EV vehicles but small decrease in Train/Tram. This is the effect of influence between agents since a large number enjoy using the own vehicle more than public transports. The larger charging capacity - $22 \mathrm{kWh}$ - also leads to great fluctuations in the demand figure with peaks reach as high as $100 \mathrm{MWh}$ then quickly go down to 0 in the next couple of hours. This is because agents can quickly charge up their vehicles at peak times then do not have more charging demand until next usage. As these scenarios only apply to one region, more careful planning is required for the national application to avoid overloading the network.

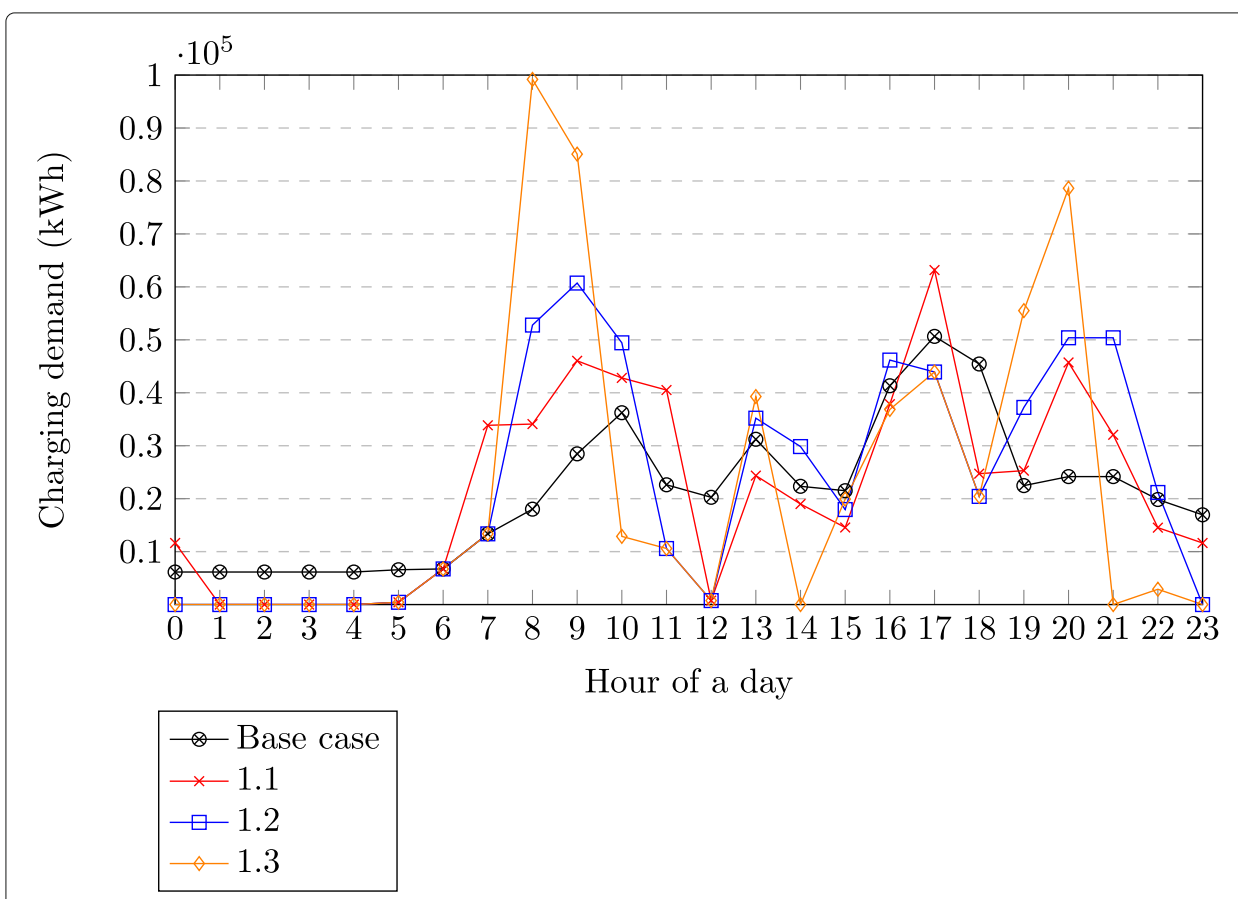

Fig. 7 Comparison of charging demand in base case and scenario that the charging rate of stations in one region is increased 
Table 5 Result of daily average mobility demand $\left(10^{6} \mathrm{~km}\right)$ by engine type in scenarios of charging price decreased

\begin{tabular}{llllll}
\hline Case number & \multirow{2}{*}{ Value of $E U_{\text {Price }}(\boldsymbol{E V} \mathbf{s})$} & \multicolumn{4}{c}{ Average daily mobility demand $\left(\mathbf{1 0}^{\mathbf{6}} \mathbf{k m}\right)$ by engine type } \\
\cline { 3 - 6 } & & Electric/Hybrid & Diesel/Gasoline & Walk/Bike & Train/Tram \\
\hline 0 & 3.7 & 56.511 & $3^{\prime} 016.546$ & 172.374 & 576.450 \\
2.1 & $-25 \%$ & 56.511 & $3^{\prime} 016.265$ & 173.407 & 575.046 \\
2.2 & $-50 \%$ & 56.836 & $3^{\prime} 016.175$ & 173.422 & 575.362 \\
2.3 & $-75 \%$ & 56.836 & $3^{\prime} 015.709$ & 173.422 & 575.422 \\
2.4 & $-100 \%$ & 56.837 & $3^{\prime} 015.813$ & 173.407 & 575.442 \\
\hline
\end{tabular}

\section{Electric charging price decreased (see Table 5 and Fig. 8)}

The effect of lowering charging price can only be seen when it is decreased by $50 \%$ and beyond. It stays stable at around 56.8 million, even when the price goes down to 0 . It appears that the price incentive has small effect on the travelling pattern since it is already quite low in the base case - CHF 0.24 per kWh (Swissgrid 2020). This also signifies that agents have taken into account not only the probability expectation of economic values but also other social and environmental differences (see "Decision-making process" section). In term of charging pattern, we observe a noticeable rise of $2 \mathrm{MWh}$ at the peak for charging demand at the hours 10-12 when the mobility demand increases.

\section{Customer's climate awareness improved (see Table 6 and Fig. 9)}

In the first two cases, the average daily mobility demand for EVs have a significant increase to more than 56.8 million kilometres. This results in the rise of several peaks in charging demand, especially at the hours of 11-12 where it reaches around $25 \mathrm{MWh}$. Travellers also walk and bike more often but than using public transport due to them being ranked more environmental friendly. When the effect of climate awareness reaches $75-100 \%$ population, the mobility demand for EV vehicles rises to more than 57.2 million kilometres. There are fewer agents use Diesel/Gasoline cars and hence, their demand decrease by 2-3 million kilometres. There are also additional charging demand at the peaks of $4 \mathrm{pm}$

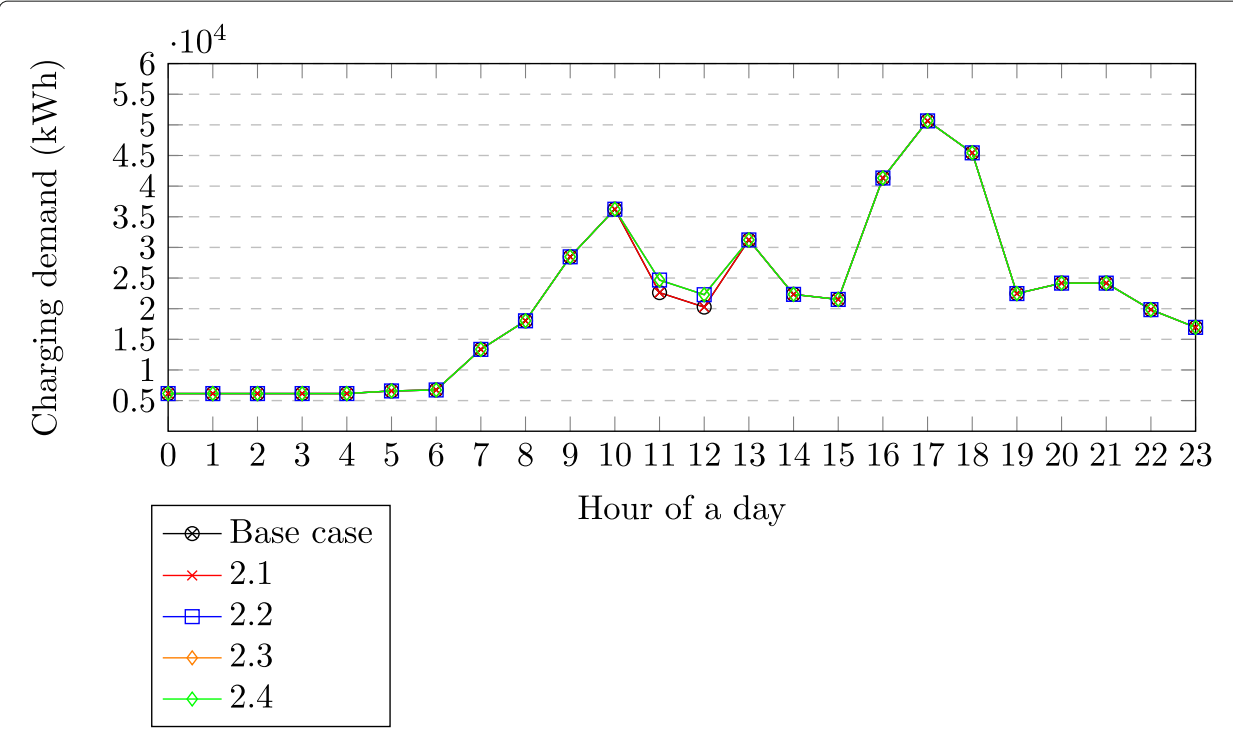

Fig. 8 Comparison of charging demand in the base case and in scenario that electric tariff is decreased 
Table 6 Result of daily average mobility demand $\left(10^{6} \mathrm{~km}\right)$ by engine type in scenarios of climate aware improved

\begin{tabular}{|c|c|c|c|c|c|}
\hline \multirow[t]{2}{*}{ Case number } & \multirow{2}{*}{$\begin{array}{l}\text { Percentages of } \\
\text { effected population }\end{array}$} & \multicolumn{4}{|c|}{ Average daily mobility demand $\left(10^{6} \mathrm{~km}\right)$ by engine type } \\
\hline & & Electric/Hybrid & Diesel/Gasoline & Walk/Bike & Train/Tram \\
\hline 0 & 3.7 & 56.511 & $3^{\prime} 016.546$ & 172.374 & 576.450 \\
\hline 3.1 & $25 \%$ & 56.845 & 3'016.293 & 172.133 & 576.754 \\
\hline 3.2 & $50 \%$ & 56.847 & $3^{\prime} 013.919$ & 173.708 & 577.727 \\
\hline 3.3 & $75 \%$ & 57.250 & $3^{\prime} 013.089$ & 173.810 & 577.776 \\
\hline 3.4 & $100 \%$ & 57.250 & $3^{\prime} 012.579$ & 174.579 & 577.484 \\
\hline
\end{tabular}

and 8pm. Overall, these figures demonstrate the effectiveness of climate policy in term of encouraging more usage of non-fossil fuelled vehicles.

\section{Discussion}

The preliminary results show that the current model is capable of demonstrating the difference in causes and effects of mobility and charging demand for EVs. Combining with the figures from other modes of transport, we can observe a variety of impacts from the three policies, which target either supply or demand side. The most effective one to motivate EV's usage is aiming to improve the population's environmental awareness. Despite being a difficult policy to execute and measure, it also could potentially encourage more demand for both public and private transports with an electric engine. Another effective method is increasing the charging rate. It is mainly due to the positive effect of customers having more access to their vehicles when the charging process finishes earlier. However, this scenario requires more infrastructure planning to manage the load at peak hours.

Some limitations need to be considered in the next development stage. The current model utilises a preset charging rate and assumes that it stays the same for the duration of a day. The model should be extended to take into account the dynamic of charging throughput, which can be diverse depending on its location and time of the day.

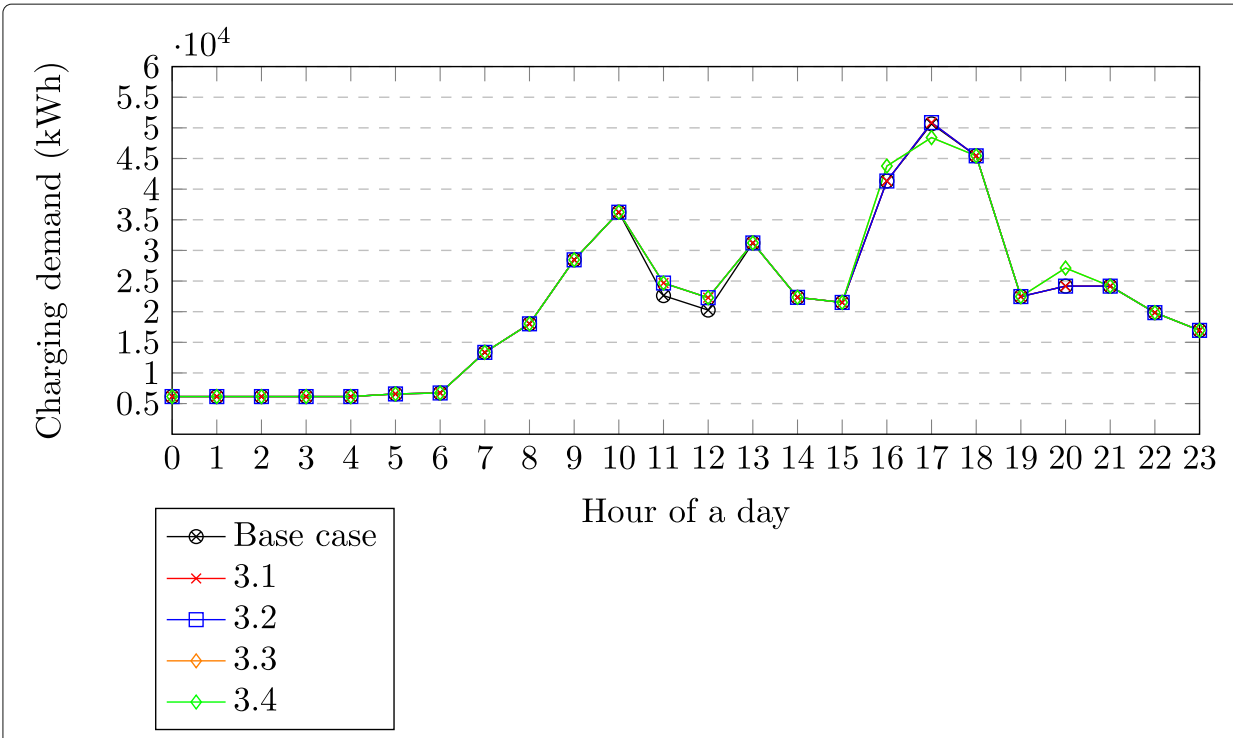

Fig. 9 Comparison of charging demand in the base case and in scenario that climate awareness is improved 
Besides, more settings, such as charging between activity and smart/controlled charging behaviours, should be considered in the future study. Further experiments can also be done with other scenario values or different variable combinations. Although the agents' decision-making weights $(w)$ are currently set according to SHEDS (Swiss Household Energy Demand Survey (SHEDS) 2017) data, their daily mobility and electricity demand can vary as they evaluate $E U$ based on their perception of the environment scenarios (see Fig. 3).

\section{Conclusion}

Several positive effects can be expected from the introduction of EVs, including reducing the carbon emissions from both power generation and transportation, and the ability to contribute to grid power quality and stability if the right infrastructure is adopted. It is important to understand the potential, limits, and impacts of combining the transportation and electricity sectors through EV technologies and simulation. A limitation of the current state-of-the-art, which is inherent in empirical (mathematical) diffusion models, is the limited ability to capture explicit social behaviour and geographical relationships between potential customers (Higgins et al. 2012). In this paper, an agent-based modal choice framework is presented, which has the potential to give insight into mobility and electric demand when combine with suitable charging scenarios. We use our simulation platform - BedDeM - to test the impacts of some policies on EVs consumption. From the three proposed, increasing charging rate was most effective though more infrastructure development is needed to handle the additional demand at top peaks. Another credible approach is to improve population environmental awareness. In addition, there are several TIB determinants contribute to the agent's decision-making process and therefore, user can explore more policies that target those factors.

The BedDeM framework is, however, still missing some features, including learning and variability. Agents do not have self-learning ability and mostly rely on the frequency of past behaviours as Habit determinant. We are developing the agent's adaptability by changing its perception of certain values or determinant weights depend on the feedbacks (success/failure) received from the environment. Coupling this along with traffic rate or different infrastructures in each region can provide a more realistic view of the shifts in behaviours of the agents. In term of the model's variability, it involves expanding the mapping between the first level determinants with SHEDS and MTMC data (see "Experimental procedure" section). This can be accomplished through our collaboration with a sociologist to derive a more precise description of TIB's elements and generate more agent profiles in the current population. Besides, investigation on the effects of changes seasonal schedules and agent's accessibility to different modes (e.g. public transports do not work well in winter condition, new routes, stations become available) is planned for the next stage.

There are also some promising research directions for our mobility platform. Using the same decision-making architecture, we can study the long-term transportation choices (such as purchasing of EVs), plus their influence on the daily routine. Moreover, the same experiment can be performed on different application domains (e.g. tourism) where TIB's determinants can potentially play a major role in the agent's decision-making. 


\section{Acknowledgements}

This project is part of the activities of SCCER CREST, which is financially supported by the Swiss Commission for Technology and Innovation (Innosuisse). The current version also utilises data from the Mobility and Transport Microcensus - 2015 edition, which provided by the Federal Office for Spatial Development (ARE) in October 2017.

\section{About this supplement}

This article has been published as part of Energy Informatics Volume 3 Supplement 1, 2020: Proceedings of the 9th DACH+ Conference on Energy Informatics. The full contents of the supplement are available online at https://energyinformatics. springeropen.com/articles/supplements/volume-3-supplement-1.

\section{Authors' contributions}

Khoa Nguyen is responsible for the writing of this paper. All authors contributed to the main concepts and experiment procedure. They have also read and approved the final manuscript.

\section{Funding}

Publication costs were covered by the DACH+ Energy Informatics Conference Organizers, supported by the Swiss Federal Office of Energy.

\section{Availability of data and materials}

Not applicable.

\section{Competing interests}

The authors declare that they have no competing interests.

\section{Published: 28 October 2020}

\section{References}

Ajzen I (1991) The theory of planned behavior. Organ Behav Hum Decis Process 50(2):179-211

ARE/BfS (2017) Verkehrsverhalten der Bevölkerung Ergebnisse des Mikrozensus Mobilität und Verkehr 2015. Fed Off Spat Dev Swiss Fed Stat Off

Bektas A, Schumann R (2019) How to Optimize Gower Distance Weights for the k-Medoids Clustering Algorithm to Obtain Mobility Profiles of the Swiss Population. In: 20196 th Swiss Conference on Data Science (SDS). IEEE. pp 51-56 Ben-Akiva ME, Lerman SR, Lerman SL, Lerman SR, MIT Press (1985) Discrete Choice Analysis: Theory and Application to Travel Demand, vol 9. MIT Press. https://books.google.ch/books?id=oLC6ZYPs9UoC

Ben-Akiva M, McFadden D, Train K, Walker J, Bhat C, Bierlaire M, Bolduc D, Boersch-Supan A, Brownstone D, Bunch DS, et al (2002) Hybrid choice models: Progress and challenges. Mark Lett 13(3):163-175

Ben-Akiva M, Walker J, Bernardino AT, Gopinath DA, Morikawa T, Polydoropoulou A (2002) Integration of choice and latent variable models. Perpetual Motion Travel Behav Res Opport Appl Challenges:431-470. https://doi.org/10.1016/ b978-008044044-6/50022-x

Brenna M, Dolara A, Foiadelli F, Leva S, Longo M (2014) Urban scale photovoltaic charging stations for electric vehicles. IEEE Trans Sustain Energy 5(4):1234-1241

Brownstone D, Bunch DS, Train K (2000) Joint mixed logit models of stated and revealed preferences for alternative-fuel vehicles. Transp Res B Methodol 34(5):315-338

Daina N, Sivakumar A, Polak JW (2017) Modelling electric vehicles use: a survey on the methods. Renew Sust Energy Rev 68:447-460

Dallinger D, Krampe D, Wietschel M (2011) Vehicle-to-grid regulation reserves based on a dynamic simulation of mobility behavior. IEEE Trans Smart Grid 2(2):302-313

Dallinger D, Wietschel M (2012) Grid integration of intermittent renewable energy sources using price-responsive plug-in electric vehicles. Renew Sust Energ Rev 16(5):3370-3382

Daziano RA (2013) Conditional-logit bayes estimators for consumer valuation of electric vehicle driving range. Resour Energy Econ 35(3):429-450

Daziano RA, Chiew E (2012) Electric vehicles rising from the dead: Data needs for forecasting consumer response toward sustainable energy sources in personal transportation. Energy Policy 51:876-894

Deng R, Yang Z, Chow M-Y, Chen J (2015) A survey on demand response in smart grids: Mathematical models and approaches. IEEE Trans Ind Inform 11(3):570-582

Druitt J, Früh W-G (2012) Simulation of demand management and grid balancing with electric vehicles. J Power Sources 216:104-116

Ensslen A, Ringler P, Dörr L, Jochem P, Zimmermann F, Fichtner W (2018) Incentivizing smart charging: Modeling charging tariffs for electric vehicles in german and french electricity markets. Energy Res Soc Sci 42:112-126

Ewing GO, Sarigöllü E (1998) Car fuel-type choice under travel demand management and economic incentives. Transp Res Part D Transp Environ 3(6):429-444

Fishbein M, Ajzen I, et al. (1975) Belief, Attitude, Intention, and Behavior: An Introduction to Theory and Research. Reading

Galus MD, Waraich RA, Noembrini F, Steurs K, Georges G, Boulouchos K, Axhausen KW, Andersson G (2012) Integrating power systems, transport systems and vehicle technology for electric mobility impact assessment and efficient control. IEEE Trans Smart Grid 3(2):934-949

Google Map. https://maps.google.com/. Accessed 24 July 2020

Higgins A, Paevere P, Gardner J, Quezada G (2012) Combining choice modelling and multi-criteria analysis for technology diffusion: An application to the uptake of electric vehicles. Technol Forecast Soc Chang 79(8):1399-1412

Hodge B-M, Shukla A, Huang S, Reklaitis G, Venkatasubramanian V, Pekny J (2011) Multi-paradigm modeling of the effects of phev adoption on electric utility usage levels and emissions. Ind Eng Chem Res 50(9):5191-5203 
Knapen L, Kochan B, Bellemans T, Janssens D, Wets G (2011) Activity based models for countrywide electric vehicle power demand calculation. In: 2011 IEEE First International Workshop on Smart Grid Modeling and Simulation (SGMS). IEEE. pp 13-18

Mobility and Transport Microcensus (2017). https://www.are.admin.ch/are/en/home/tr-ansport-and-infrastructure/data/ mtmc.html. Accessed 16 Jan 2019

Moreira C, Lopes JP, Almeida PR, Seca L, Soares FJ (2011) A stochastic model to simulate electric vehicles motion and quantify the energy required from the grid. https://repositorio.inesctec.pt/handle/123456789/2210

Mullan J, Harries D, Bräunl T, Whitely S (2011) Modelling the impacts of electric vehicle recharging on the western australian electricity supply system. Energy Pol 39(7):4349-4359

Mwasilu F, Justo JJ, Kim E-K, Do TD, Jung J-W (2014) Electric vehicles and smart grid interaction: A review on vehicle to grid and renewable energy sources integration. Renew Sust Energy Rev 34:501-516

Nguyen K, Schumann R (2019) On developing a more comprehensive decision-making architecture for empirical social research : lesson from agent-based simulation of mobility demands in Switzerland. 20th Int Work Multi-Agent-Based Simul (MABS 2019):12. http://hesso.tind.io/record/4263

Nourinejad M, Chow JY, Roorda MJ (2016) Equilibrium scheduling of vehicle-to-grid technology using activity based modelling. Transp Res Part C Emerg Technol 65:79-96

Plugshare (2020) Charging location map. https://www.plugshare.com. Accessed 11 May 2020

Qian K, Zhou C, Allan M, Yuan Y (2010) Modeling of load demand due to ev battery charging in distribution systems. IEEE Trans Power Syst 26(2):802-810

Richardson DB (2013) Electric vehicles and the electric grid: A review of modeling approaches, impacts, and renewable energy integration. Renew Sust Energy Rev 19:247-254

Rome2rio website. https://www.rome2rio.com/map/Sion/Sierre. Accessed 24 July 2020

Rosenfeld A, Kraus S (2018) Predicting human decision-making: From prediction to action. Synth Lect Artif Intell Mach Learn 12(1):1-150

Shepero M, Munkhammar J (2018) Spatial markov chain model for electric vehicle charging in cities using geographical information system (gis) data. Appl Energy 231:1089-1099

Sierzchula W, Bakker S, Maat K, Van Wee B (2014) The influence of financial incentives and other socio-economic factors on electric vehicle adoption. Energy Pol 68:183-194

Sovacool BK, Ryan SE, Stern PC, Janda K, Rochlin G, Spreng D, Pasqualetti MJ, Wilhite H, Lutzenhiser L (2015) Integrating social science in energy research. Energy Res Soc Sci 6:95-99

Swiss Household Energy Demand Survey (SHEDS) (2017). https://www.sccer-crest.ch/research/swiss-household-energydemand-survey-sheds/. Accessed 16 Jan 2019

Swissgrid (2020) Transmission grid: costs for consumers will remain the same in 2020. https://www.swissgrid.ch/en/ home/about-us/newsroom/newsfeed/20190322-01.html. Accessed 21 May 2020

The Repast Suite. https://repast.github.io. Accessed 24 Jan 2020

Triandis HC (1977) Interpersonal behavior. Brooks/Cole Pub. Co.

UNIVOX (2020) UNIVOX Umwelt 2018. https://gfs-zh.ch/wp-content/uploads/2018/11/gfszh_Ux-Umwelt-2018_def.pdf. Accessed 21 May 2020

Walker J, Ben-Akiva M (2002) Generalized random utility model. Math Soc Sci 43(3):303-343

Wang Y, Infield D (2018) Markov chain monte carlo simulation of electric vehicle use for network integration studies. Int J Electr Power Energy Syst 99:85-94

Wang J, Liu C, Ton D, Zhou Y, Kim J, Vyas A (2011) Impact of plug-in hybrid electric vehicles on power systems with demand response and wind power. Energy Pol 39(7):4016-4021

Waraich RA, Galus MD, Dobler C, Balmer M, Andersson G, Axhausen KW (2013) Plug-in hybrid electric vehicles and smart grids: Investigations based on a microsimulation. Transp Res Part C Emerg Technol 28:74-86

Weber S, Burger P, Farsi M, Martinez-Cruz AL, Puntiroli M, Schubert I, Volland B (2017) Swiss household energy demand survey (sheds): Objectives, design, and implementation. Technical report, IRENE Working Paper

Xiang Y, Hu S, Liu Y, Zhang X, Liu J (2019) Electric vehicles in smart grid: a survey on charging load modelling. IET Smart Grid 2(1):25-33

Zakariazadeh A, Jadid S, Siano P (2014) Multi-objective scheduling of electric vehicles in smart distribution system. Energy Convers Manag 79:43-53

Zakariazadeh A, Jadid S, Siano P (2015) Integrated operation of electric vehicles and renewable generation in a smart distribution system. Energy Convers Manag 89:99-110

\section{Publisher's Note}

Springer Nature remains neutral with regard to jurisdictional claims in published maps and institutional affiliations. 